\section{Consumidor Financiero y la necesidad de un actor que articule los esfuerzos orientados a mejorar su bienestar $^{*}$}

Fernando López

Ph.D. en Finanzas, Washington University

in St. Lonis, Estados Unidos.

Contrario a los supuestos de racionalidad en que se basa la reoria del consumidor -y que recitan los estudiantes de ingeniebrecha enorme entre las habilidades del consumidor financiero y el grado de complejidad asociada a la administración de sus finanzas personales (Figura 1). Esta falta de habilidades no debería sorprendernos porque en la práctica sabemos poco y nada acerca de un sinnúmero de temas, como plantar una lechuga o comu-
nicarnos en nepali. Esto tampoco debería preocuparnos mucho porque saber cómo plantar una lechuga o entender nepali poco afecta nuestra calidad de vida. En el caso de las habilidades financieras, la situación es diferente.

Figura 1

llustración del desafio que enfrenta el consumidor financiero

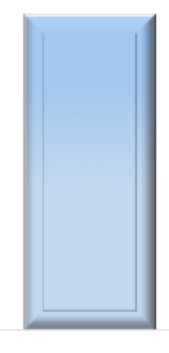

Habilidades y conocimientos Complejidad de las decisiones financieros
¿POR QUÉ NOS PREOCUPAMOS DE LA FALTA DE HABILIDADES FILACION?

La falta de habilidades financieras podría ocasionarnos costos significativos a nivel individual y a nivel agregado. El costo más obvio es el que experimentan las personas que toman decisiones ción media que no se prepara adecuadamente para postular a ciamiento necesarias para costear su educación. Este estudiante ria, acceder a un mayor numero de alternativas de empleo que eventualmente coinciden con su vocación y un mayor nivel de dos $y$ los años que podrían has asociadas a los recursos invertimedida que estos err res sean masivos, a falta de conocine En y habilidades financeras podria incluso afectar el nive agregas de capital humano y la productividad de la economia.

Un segundo costo de la falta de habilidades financieras de los consumidores es que distorsiona los incentivos de algunos actores de la industria financiera para competir. Por ejemplo, un vendedor de servicios financieros que recibe comisiones difeenciadas segun los productos que vende tendrá incentivos para vender aquellos servicios con que obtendrá mayores comisiones y no necesariamente los más idóneos para su cliente. A nivel corpo-
lativo, la falta de habilidades financieras podria representar una universidades debido a que no conoce las posibilidades de finanpodria perder la oportunidad de vivir la experiencia universitaingreso laboral. Del mismo modo, estudiantes que sin saberlo se endeudan para ingresar a carreras con baja empleabilidad podrián fuente de poder de mercado que permita acceder a ganancias superiores a las que obtendrian en un mercado con consumidores sofisticados.

Un tercer costo es el eventual deterioro de la legitimidad de algunos actores de la industria financiera, como ocurrí con las poco informado podría dar respaldo politico a ideas que tiene una apariencia atractiva pero que podrian perjudicarlo.

AVANCES EN EDUCACIÓN FINANCIERA

En la ultima decada se han realizado una serie de iniciativas para promover la educación financiera. Entre estas, se han desarrollado numerosos programas educativos, se han implementado encuestas para cuantificar el nivel de conocimiento y conductas financieras (LPS, CAF-SBIF, Casen, LF), se instauró la celebración de la semana y el mes de la educación financiera, se creó una Coley que propone lucaín finarier obliga un proyecto de básica y media Uno de los principales frutos de los esfuerzos realizados por instituciones publicas $y$ privadas es que hoy tenemos más conciencia de las dificultades que tienen las personas pas administrar sus recursos financieros.

UN MERCADO MÁS AMIGABLE

Una alternativa que complementa la educación financiera es la simplificacion y orientación de la toma de decisiones por parte de los consumidores. En esta linea se han implementado tres tipos de medidas. Primero, instaurar la obligatoriedad de contratar servicios financieros considerados imprescindibles como el ahorro previsional, seguro de salud, multifondos, seguro obligatorio de accidentes personales (SOAP) y seguro accidentes laborales. Segundo, aumentar la transparencia en la entrega de información. por ejemplo, a rraves da mutuos. Tercero, establecer licitaciones que minimicen el precio y garanticen un nivel minimo de calidad de algunos servicios financieros como la administración de cotizaciones previsionales des trabajadores que se incorporan al sistema de pensiones, seguros de créditos hipotecarios $y$ seguros de invalidez y sobrevivencia asociados a los ahorros previsionales.

Pese a que muchas de estas medidas no cuentan con evaluaciones de impacto, se aprecia que hoy es màs facil informarse sobre temas relacionados con las finanzas personales, tanto porque tenemos un mayor acceso a información como porque contamos con un mercado mucho más amigable de lo que era hace años atras. Sin embargo, las habilidades del consumidor financiero $\mathrm{s}$ guen siendo insuficientes para abordar la complejidad de las de-

LA NECESIDAD DE UN ACTOR CON UNA MIRADA INTEGRAL Para avanzar en materias de educación financieras y simplifica requiere una entidad (o un actor dentro de una entidad) con dedicación exclusiva con competencias técnicas y politicas, capaz de elaborar una estrategia de largo plazo que articule los esfuerzos de distintos actores. Esta entidad deberia tener objetivos concre- tos, plazos definidos, atribuciones especificas y un presupuesto razonable que le permita desarrollar su quehacer. de un

Primero, la naturaleza y envergadura del problema requiere de una mirada sistémica que dificilmente podría entregar alguna de vadas han abordado los problemas que enfrenta el consumido financiero desde sus ámbitos de competencia. Sin embargo, no se ha logrado un enfoque "integral" que permita identificar prioridades y desarrollar instrumentos (probados cientificamente) que contribuyan a mejorar la administración de las finanzas persona-

En términos de prioridades, inclusión financiera, endeudamiento responsable y pensiones son los temas que han recibido ma yor atención. Sin duda, estos son altamente relevantes porque significativa de los consumidoes para abordanlos podria afectar margo, hay otros temas de tanto o mís impacto ave no ha ido abordados de manera adecuada Ouizás el caso más preocupante corresponde a las decisiones de los jóvenes respecto a su educación, uno de los principales determinantes de empleabilidad y salarios durante su ciclo de vida. Pese a su relevancia, la evidencia disponible para Chile sugiere que muchos jóvenes no entienden ni consideran las implicancias económicas asociadas a las distintas trayectorias educacionales que podrian seguir. Conside-

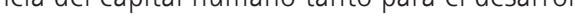
individual como para la productividad de la economía, analizar ser un tema prioritario.

Segundo, el mundo académico no tiene incentivos suficientes para desarrollar los estudios que se necesitan como base par

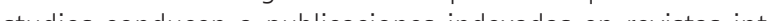
nacionales y por tanto, no son apreciados en las postulaciones concursos de investigación (Como FONDECYT). Del mismo modo. a mayoria de las instituciones a nivel nacional no considera mérito de estas investigaciones en sus evaluaciones para efectos academica.

Por ultimo, para ilustrar la importancia de la dedicación exclusiva, vale la pena recordar la "Comisión para la Inclusión Financie(Cobision fue creada en 2014 con el objeto de desarrollar ana sstrategia para mejorar el bienestar del consumidor financiro. Sin embargo, su incidencia ha sido acotada. En parte, esto se que a que está integrada por los titulares de cinco ministerios que tienen que dividir sus esfuerzos y atención en proyectos vinno es necesariamente una prioridad.

"Este articulo se basa en el estudio del mismo autor: "Consumidor Financiero: Diag-
nostico y Alounas Propuestas", por aparcece en el libro: "Crisis Financieras: Lecciones 